\title{
Biometric relationships for non-destructive above ground biomass estimations in young plantations of Acacia salicina Lindl. and Eucalyptus occidentalis Endl.
}

\author{
HARRIE M. LÖVENSTEIN ${ }^{1}$ and PEDRO R. BERLINER ${ }^{2}$ \\ ${ }^{\prime}$ Department of Theoretical Production Ecology, Agricultural University Wageningen, \\ PO Box 430, 6700 AK Wageningen, The Netherlands; ${ }^{2}$ Runoff Agriculture Unit, \\ Jacob Blaustein Institute for Desert Research, 84990 Sede Boqer Campus, Israel
}

Received 7 January 1991; accepted 22 September 1992

Key words: arid lands, coppicing, fuelwood, hardwoods, multiple stems, plant density, sampling techniques, short rotation, sprouting

Application. Monitoring of fuelwood production by individual trees in young plantations of Eucalyptus occidentalis Endl. and (multiple stem) Acacia salicina Lindl. under short $(2-3$ years) rotations and estimating biomass of multiple and single stem trees of these species.

\begin{abstract}
Above ground oven dried biomass (BM) of individual trees in young stands of Acacia salicina Lindl. and Eucalyptus occidentalis Endl. were correlated linearly and logarithmically to the square of the basal diameter at $0.2 \mathrm{~m}(\mathrm{DB})$ and to the latter multiplied by the height of the tree. Number of main stems at basal height per tree were included as well. DB measurements in young Eucalypt stands provided better BM estimates than the commonly used diameter at breast height $(1.3 \mathrm{~m})(\mathrm{DBH})$.

The following biometric relationships, after cross-validation against an independent data set, showed the best fit: $\mathrm{BM}=0.1282 * \Sigma\left(\mathrm{DB}^{2}\right)$ and $\mathrm{BM}=0.1700 * \Sigma\left(\mathrm{DB}^{2}\right)$ for $A$. salicina and E. occidentalis, respectively, with $\Sigma\left(\mathrm{DB}^{2}\right)$ ranging from $0-400 \mathrm{~cm}^{2}$ and $\mathrm{BM}$ in $\mathrm{kg}$ tree $\mathrm{e}^{-1}$. For acceptable relative errors in biomass estimations $\Sigma\left(\mathrm{DB}^{2}\right)$ should be larger than $100 \mathrm{~cm}^{2}$.

Foliage to wood ratios at $\Sigma\left(\mathrm{DB}^{2}\right)<100 \mathrm{~cm}^{2}$ for both tree species generally exceeded 1 , but rapidly leveled off at $0.81 \pm 0.28$ and $0.92 \pm 0.19$ for the Acacia and Eucalypt spp., respectively, at higher $\Sigma\left(\mathrm{DB}^{2}\right)$ values.
\end{abstract}

\section{Introduction}

More than a billion people, of which a majority lives in arid and semiarid regions, presently experience fuelwood shortages and this number is likely to almost triple by the end of the century (Agric. Univ. Wageningen 1983; Sirin and Mitchell 1985). Fuelwood plantations with mainly fast growing tree species under short rotation cycles may alleviate this problem (NAS 1986). Paradoxically, however, little information about tree development 
is available in arid areas in which they are desperately needed (Zohar et al. 1988). Assessment of yields and optimum management techniques (planting density, harvesting rotation) require the monitoring of tree growth. Felling trees throughout the period of interest would lead to largescale experiments. Non-destructive biomass measurements are therefore preferred. Easily measured tree parameters (height $(\mathrm{H})$, diameter at tree base (a height of $0.2 \mathrm{~m})(\mathrm{DB})$ and diameter at breast height (a height of $1.3 \mathrm{~m})(\mathrm{DBH})$ have been used for non-destructive estimates of (above ground) biomass (BM) in biometric models. The most commonly used models are (Causton 1985; Stewart et al. 1979; Whittaker and Marks 1975):

$$
\begin{array}{ll}
\text { linear model }(\mathrm{LIN}): & \text { yield }=a+b * \text { PARAM } \\
\text { logarithmic model }(\mathrm{LOG}): & \text { LOG }(\text { yield })=a+b * \text { LOG }(\text { PARAM })
\end{array}
$$

where PARAM represents either $\mathrm{DBH}^{2}, \mathrm{DBH}^{2} * \mathrm{H}, \mathrm{DB}^{2}$ or $\mathrm{DB}^{2} * \mathrm{H}$, with yield expressed as volume or weight (fresh or dry) per tree. Even though there is a theoretical justification for the use of LOG (or allometric) models (Causton 1985), LIN models frequently perform satisfactorily (Brewbaker 1987; Hawkins 1987).

In mature stands DBH is used (e.g. Abbott and Loneragan 1983; Chidumayo 1988; West 1979; Bredenkamp 1982), because of its convenience. However, in young stands $\mathrm{DBH}$ may not be sufficiently developed to be introduced in biometric models, in which case DB would appear to be more relevant.

$\mathrm{H}$ is often included in biometric relationships, even though its assessment, especially for tall trees, is difficult and inaccurate (Clough and Scott 1989). Furthermore, as older trees gain weight without increasing height (Abbott and Loneragan 1982), $\mathrm{H}$ appears to be a less meaningful biomass indicator. In young tree stands, however, $\mathrm{H}$ is relatively easy to measure with greater accuracy and may improve biomass estimates.

During early development stages some tree species exhibit multiple stems with usually one or a few developing into dominant stems. If primary branching points (particularly in younger tree stands) are located below DBH, measurement of DB would be advantageous. However, when these branching points start below DB (e.g. tree species characterized by a shrubby growth form or coppice shoots), stem number should be considered as well in the biomass estimation.

Fast growing trees in fuelwood plantations are frequently harvested while still young ( $2-3$ years after planting). Hence, the equations mentioned earlier and the underlying assumptions which hold true for mature 
trees, should be rigorously tested for young tree stands. Acacia salicina and Eucalyptus occidentalis (referred to as Acacia and Eucalypt, respectively) appear to be suitable for fuelwood production in runoff systems in arid zones (Zohar et al. 1988). No biometric relationships for these particular species have been published.

The objectives of the present study were to

a) determine which of the above mentioned equations $(1,2)$ describes best the above ground biomass production,

b) cross-validate these equations,

c) determine how to predict biomass of multi-stem trees,

d) assess the dependence of foliage to wood ratio on DB,

for 3 year old plantations of Acacia and Eucalypt.

\section{Materials and methods}

Plantations were established as part of an agroforestry research project at the experimental runoff farm at Wadi Mashash in the Negev desert of Israel, located $20 \mathrm{~km}$ south of Beer Sheva and $60 \mathrm{~km}$ from the Mediterranean $\left(31^{\circ} 08^{\prime} \mathrm{N}, 34^{\circ} 53^{\prime} \mathrm{E}\right)$ at an elevation of $400 \mathrm{~m}$ a.s.l..

Mean annual rainfall (1971-1988), concentrated in the winter period, is $115 \mathrm{~mm}$, and is highly variable both in amount and distribution. Class A pan evaporation is of the order of $2500-3000 \mathrm{~mm} \mathrm{a}^{-1}$. The climate is characterized as BWhs and BShs (i.e. winter rainfall in hot desert and steppes) according to Köppen's classification (Köppen and Geiger 1936).

Soils are characterized by a $2 \mathrm{~m}$ deep loessial deposit with a high water holding capacity $(17 \% \mathrm{v} / \mathrm{v})$. Profiles are relatively homogeneous with occasional thin layers of fine gravel or coarse sand starting at $1 \mathrm{~m}$ depth. In deeper layers more gravel is found, with lime and flint stones.

In January 1986 Acacia and Eucalypt seedlings were planted in four macro catchment basins of approximately 0.3 ha each. These structures allow for the trapping of runoff water (i.e. rain water harvesting) as the sole water source for tree production. Typically $500-600 \mathrm{~mm}$ of water are annually added to the soil profile in these basins during runoff events, 5 times more than the mean annual rainfall (Lövenstein et al. 1991). The layout of these basins in the field is such that they usually receive unequal overall amounts of water during the rainy season, whereas also within each basin water is not evenly distributed. Both species were grown in plots of $12 \times 16 \mathrm{~m}$ at two densities: 625 trees ha $^{-1}(4 \times 4 \mathrm{~m}-$ open spacing) and 1250 trees $\mathrm{ha}^{-1}(4 \times 2 \mathrm{~m}-$ dense spacing $)$. Plots of each species and spacing were randomly replicated twice in each basin. A 
detailed description of the experimental setup may be found in Lövenstein et al. (1991).

In December 1988 all trees were felled, leaving a trunk of $0.2 \mathrm{~m}$ height (to allow regeneration of coppice shoots) and individually weighed (Table 1). Prior to felling, tree height $(\mathrm{H})$ using a measuring-staff and diameter at cut end (DB) using a girthing tape were recorded per tree, measuring all girths separately for multiple stems trees. For single stem Eucalypts diameter at $1.30 \mathrm{~m}(\mathrm{DBH})$ was also recorded. Diameter measurements derived from girthing tapes are preferable to those commonly obtained by (perpendicular) vernier callipers, as the latter may result in larger reading errors for irregularly shaped, small-sized stems of young trees.

Ten randomly selected trees per plot were partitioned into foliage (branch diameter $<1 \mathrm{~cm}$ ) and woody components (branch diameter $\geqslant 1$ $\mathrm{cm})$, representing the fodder and firewood components, respectively (Table 1). Subsamples were oven dried $\left(70^{\circ} \mathrm{C}\right)$ to assess total dry matter.

Total above ground dry matter was related to $\mathrm{DB}^{2}, \mathrm{DBH}^{2}$, and $\mathrm{H}$ using linear (LIN), linear forced through the origin (FOR) and allometric (LOG) models. In multiple stemmed trees the cross sectional area was obtained by summing the areas of the different stems and not by using an average diameter value (Bashir et al. 1989). Boundary trees in a basin, were excluded from the analysis. Data were arbitrarily divided in two groups of two macro catchment basins each with an approximately equal number of trees. Regression coefficients were computed in one group (primary regressions) and cross-validated in the other (cross-validation regressions) (Snee 1977). The goodness of fit (agreement with 1:1) was evaluated by determining precision (reflected in $\mathrm{R}^{2}$ ) and accuracy (deviation of intercept and slope from 0 and 1, respectively) for the cross-validation regressions (i.e. predicted versus observed values). In order to determine whether planting density and/or stem number affected the proposed relationships, slopes and intercepts of the obtained primary regressions were compared using $t$-tests (Zar 1984). The best model for each tree species was selected on the basis of the cross-validation regressions.

\section{Results and discussion}

Mean values and ranges of measured parameters for both data sets are listed in Table 1. The generally better performance of trees used for the cross-validation regressions is apparently due to higher water availability in the corresponding macro catchment basins. Although even-aged stands were studied, large variation in productivity was observed within the same basin, probably due to genetic heterogeneity in seedlings as well as uneven water distribution. 
Table 1. Mean value and range of measured height $(\mathrm{H})$, diameter at stem base height of $20 \mathrm{~cm}(\mathrm{DB})$ or at breast height (DBH), stem number at stem base (SNB) or at breast height (SNBH), and weight of dry foliage (BMFOL), drywood (BMWOOD) and total dry above ground biomass (BMTOT), for Acacia salicina (ACA) and Eucalyptus occidentalis (EUC) in the primary (P) and cross-validation (C) data set. ( $n$ : number of trees per data set).

\begin{tabular}{|c|c|c|c|c|c|c|c|c|c|c|}
\hline \multirow{2}{*}{$\begin{array}{l}\text { data set } \\
P\end{array}$} & \multirow{2}{*}{$\begin{array}{l}\text { tree } \\
\mathrm{ACA}\end{array}$} & \multirow{2}{*}{$\begin{array}{l}\mathrm{n}^{\mathrm{a}} \\
70(43)\end{array}$} & \multirow{2}{*}{$\begin{array}{l}\mathrm{H}(\mathrm{in} \mathrm{m}) \\
\operatorname{mean}(\min -\max ) \\
3.40(1.6-5.3)\end{array}$} & \multirow{2}{*}{$\begin{array}{l}\mathrm{DB}(\mathrm{in} \mathrm{cm}) \\
\text { mean }(\mathrm{min}\end{array}$} & \multirow{2}{*}{$\begin{array}{l}-\max ) \\
-51.0)\end{array}$} & \multirow{2}{*}{$\begin{array}{l}\mathrm{DBH}(\text { in } \mathrm{cm}) \\
\text { mean }(\min -\max ) \\
\text { - }^{\mathrm{b}}\end{array}$} & \multicolumn{2}{|c|}{$\begin{array}{l}\text { SNB } \\
\text { mean }(\min -\max )\end{array}$} & \multicolumn{2}{|c|}{$\begin{array}{l}\text { SNBH } \\
\text { mean }(\min -\max )\end{array}$} \\
\hline & & & & & & & 1.63 & $(1-5)$ & & $-^{\mathrm{b}}$ \\
\hline $\mathrm{P}$ & EUC & $79(47)$ & $5.74(2.1-8.5)$ & $31.76(11.0$ & $-51.5)$ & $21.56(4.0-34.5)$ & 1.21 & $(1-3)$ & 1.84 & $(1-4)$ \\
\hline $\mathrm{C}$ & $\mathrm{ACA}$ & $85(48)$ & $3.66(2.0-5.3)$ & $27.12 \quad(9.0$ & $-53.5)$ & $-^{\mathrm{b}}$ & 1.63 & $(1-4)$ & & $-^{\mathrm{b}}$ \\
\hline $\mathrm{C}$ & EUC & $71(42)$ & $5.99(2.2-7.7)$ & $32.52(11.0$ & $-54.0)$ & $21.28(4.5-32.5)$ & 1.22 & $(1-5)$ & 2.14 & $(1-7)$ \\
\hline & & & $\begin{array}{l}\left.\text { BMFOL (in kg tree }{ }^{-1}\right) \\
\text { mean }(\min -\text { max) }\end{array}$ & $\begin{array}{l}\text { BMWOOD } \\
\text { mean (min }\end{array}$ & $\begin{array}{l}\left(\text { in } k g \text { tree }{ }^{-1}\right) \\
-\max )\end{array}$ & $\begin{array}{l}\text { BMTOT (in kg tree }{ }^{-1} \text { ) } \\
\text { mean }(\min -\max )\end{array}$ & & & & \\
\hline $\mathrm{P}$ & ACA & & $7.43(1.99-14.35)$ & $8.61 \quad(0.80$ & $0-18.94)$ & $14.45(1.24-37.09)$ & & & & \\
\hline $\mathrm{P}$ & EUC & & $12.08(1.85-24.48)$ & $11.92 \quad(1.42$ & $2-25.90)$ & $22.40(1.99-50.38)$ & & & & \\
\hline $\mathrm{C}$ & $\mathrm{ACA}$ & & $8.26(1.54-21.78)$ & $10.59(0.97$ & $7-36.52)$ & $17.15(1.14-58.30)$ & & & & \\
\hline $\mathrm{C}$ & EUC & & $12.60(2.98-29.15)$ & $13.40 \quad(2.54$ & $4-29.11)$ & $23.84(1.48-58.26)$ & & & & \\
\hline
\end{tabular}

a number in parenthesis indicate the number of trees out of total trees per dataset (n) for which foliage (BMFOL) and wood (BMWOOD) were weighted separately.

b The shrubby growth form of ACA, characterized by a large number of small-sized branches at breast height (usually more than 10) precludes $\mathrm{DBH}$ as an useful biomass estimator. 
Table 2. Linear (LIN), logarithmic (LOG) and through the origin forced linear (FOR) regression models for the estimation of above ground dry matter $\left(\mathrm{kg}\right.$ tree ${ }^{-1}$ ) of Acacia salicina (ACA) and Eucalyptus occidentalis (EUC).

\begin{tabular}{|c|c|c|c|c|c|c|c|c|c|c|c|c|c|c|c|c|c|c|}
\hline \multirow[b]{2}{*}{ tree } & \multirow[b]{2}{*}{ stem } & \multirow[b]{2}{*}{ model } & \multirow[b]{2}{*}{ param } & \multicolumn{6}{|c|}{ Primary regressions } & \multirow[b]{2}{*}{$\mathrm{R}^{2}$} & \multicolumn{2}{|c|}{ Model test } & \multicolumn{6}{|c|}{ Cross-validation regressions } \\
\hline & & & & intercept & slope & $P_{\text {int }}$ & $\mathrm{P}_{\mathrm{slp}}$ & $\mathrm{n}$ & SEE & & $\mathrm{P}_{\text {slp }}$ & $P_{\text {int }}$ & intercept & slope & $P_{i n t}$ & $\mathrm{P}_{\text {slp }}$ & $\mathrm{n}$ & $\mathrm{R}^{2}$ \\
\hline ACA & SNG & LIN & $\Sigma\left(\mathrm{DB}^{2}\right)$ & -0.5996 & 0.1325 & ns & $* * *$ & 44 & 3.23 & 84.55 & ns & ns & -1.383 & 1.088 & ns & ns & 51 & 80.77 \\
\hline $\mathrm{ACA}$ & MUL & LIN & $\Sigma\left(\mathrm{DB}^{2}\right)$ & -1.8291 & 0.1405 & ns & $* * *$ & 26 & 2.72 & 88.65 & & & 0.448 & 0.817 & ns & $* *$ & 34 & 85.17 \\
\hline $\mathrm{ACA}$ & TOT & LIN & $\Sigma\left(\mathrm{DB}^{2}\right)$ & -0.9258 & 0.1348 & ns & $* * * *$ & 70 & 3.01 & 86.66 & & & 0.260 & 0.914 & ns & * & 85 & 78.52 \\
\hline $\mathrm{ACA}$ & SNG & LIN & $\Sigma\left(\mathrm{DB}^{2}\right) * \mathrm{H}$ & 2.2135 & 0.0286 & $*$ & $* * * *$ & 44 & 3.26 & 84.25 & $\mathrm{~ns}$ & ns & 0.162 & 0.992 & $\mathrm{~ns}$ & ns & 51 & 80.83 \\
\hline $\mathrm{ACA}$ & MUL & LIN & $\Sigma\left(\mathrm{DB}^{2}\right) * \mathrm{H}$ & 3.8438 & 0.0264 & $* *$ & $* * *$ & 26 & 3.03 & 85.85 & & & -0.941 & 0.904 & ns & ns & 34 & 84.57 \\
\hline $\mathrm{ACA}$ & TOT & LIN & $\Sigma\left(\mathrm{DB}^{2}\right) * \mathrm{H}$ & 2.7139 & 0.0279 & $* * *$ & $* * *$ & 70 & 3.16 & 85.32 & & & 0.404 & 0.912 & ns & $*$ & 85 & 80.09 \\
\hline $\mathrm{ACA}$ & $\mathrm{SNG}$ & LOG & $\Sigma\left(\mathrm{DB}^{2}\right)$ & -2.4782 & 1.0789 & $* * *$ & $* * *$ & 44 & 3.24 & 88.55 & ns & ns & -0.796 & 1.085 & ns & $\mathrm{ns}$ & 51 & 80.68 \\
\hline $\mathrm{ACA}$ & MUL & LOG & $\Sigma\left(\mathrm{DB}^{2}\right)$ & -2.8277 & 1.1512 & $* * *$ & $* * *$ & 26 & 2.87 & 88.13 & & & 1.413 & 0.768 & $\mathrm{~ns}$ & $* * *$ & 34 & 84.43 \\
\hline $\mathrm{ACA}$ & TOT & LOG & $\Sigma\left(\mathrm{DB}^{2}\right)$ & -2.5241 & 1.0887 & $* * *$ & $* * *$ & 70 & 3.03 & 89.27 & & & 0.842 & 0.901 & $\mathrm{~ns}$ & $*$ & 85 & 78.02 \\
\hline $\mathrm{ACA}$ & SNG & LOG & $\Sigma\left(\mathrm{DB}^{2}\right) * \mathrm{H}$ & -2.2763 & 0.8177 & $* * *$ & $* * * *$ & 44 & 3.12 & 90.47 & ns & ns & -0.652 & 1.065 & ns & ns & 51 & 81.85 \\
\hline ACA & MUL & LOG & $\Sigma\left(\mathrm{DB}^{2}\right) * \mathrm{H}$ & -2.0318 & 0.7846 & $* * *$ & $* * * *$ & 26 & 3.01 & 85.88 & & & -1.490 & 0.948 & $\mathrm{~ns}$ & ns & 34 & 85.63 \\
\hline $\mathrm{ACA}$ & TOT & LOG & $\Sigma\left(\mathrm{DB}^{2}\right) * \mathrm{H}$ & -2.2650 & 0.8187 & $* * * *$ & $* * * *$ & 70 & 3.04 & 90.31 & & & -0.181 & 0.961 & ns & ns & 85 & 81.31 \\
\hline $\mathrm{ACA}$ & SNG & FOR & $\Sigma\left(\mathrm{DB}^{2}\right)$ & & 0.1280 & & $* * *$ & 44 & 3.20 & 95.72 & ns & & -2.036 & 1.127 & ns & ns & 51 & 80.77 \\
\hline ACA & MUL & FOR & $\Sigma\left(\mathrm{DB}^{2}\right)$ & & 0.1285 & & $* * *$ & 26 & 2.75 & 97.86 & & & -1.047 & 0.893 & ns & $\mathrm{ns}$ & 34 & 85.17 \\
\hline $\mathrm{ACA}$ & TOT & FOR & $\Sigma\left(\mathrm{DB}^{2}\right)$ & & 0.1282 & & $* * * *$ & 70 & 3.01 & 96.74 & & & -0.586 & 0.960 & ns & ns & 85 & 78.52 \\
\hline $\mathrm{ACA}$ & SNG & FOR & $\Sigma\left(\mathrm{DB}^{2}\right) * \mathrm{H}$ & & 0.0326 & & $* * * *$ & 44 & 3.46 & 95.01 & ns & & 2.357 & 0.870 & * & $*$ & 51 & 80.83 \\
\hline $\mathrm{ACA}$ & MUL & FOR & $\Sigma\left(\mathrm{DB}^{2}\right) * \mathrm{H}$ & & 0.0324 & & $* * *$ & 26 & 3.53 & 96.45 & & & 2.533 & 0.736 & $*$ & $* * * *$ & 34 & 84.57 \\
\hline $\mathrm{ACA}$ & TOT & FOR & $\Sigma\left(\mathrm{DB}^{2}\right) * \mathrm{H}$ & & 0.0325 & & $* * *$ & 70 & 3.46 & 95.69 & & & 2.879 & 0.783 & $* * *$ & $* * *$ & 85 & 80.09 \\
\hline
\end{tabular}


Table 2 (Continued).

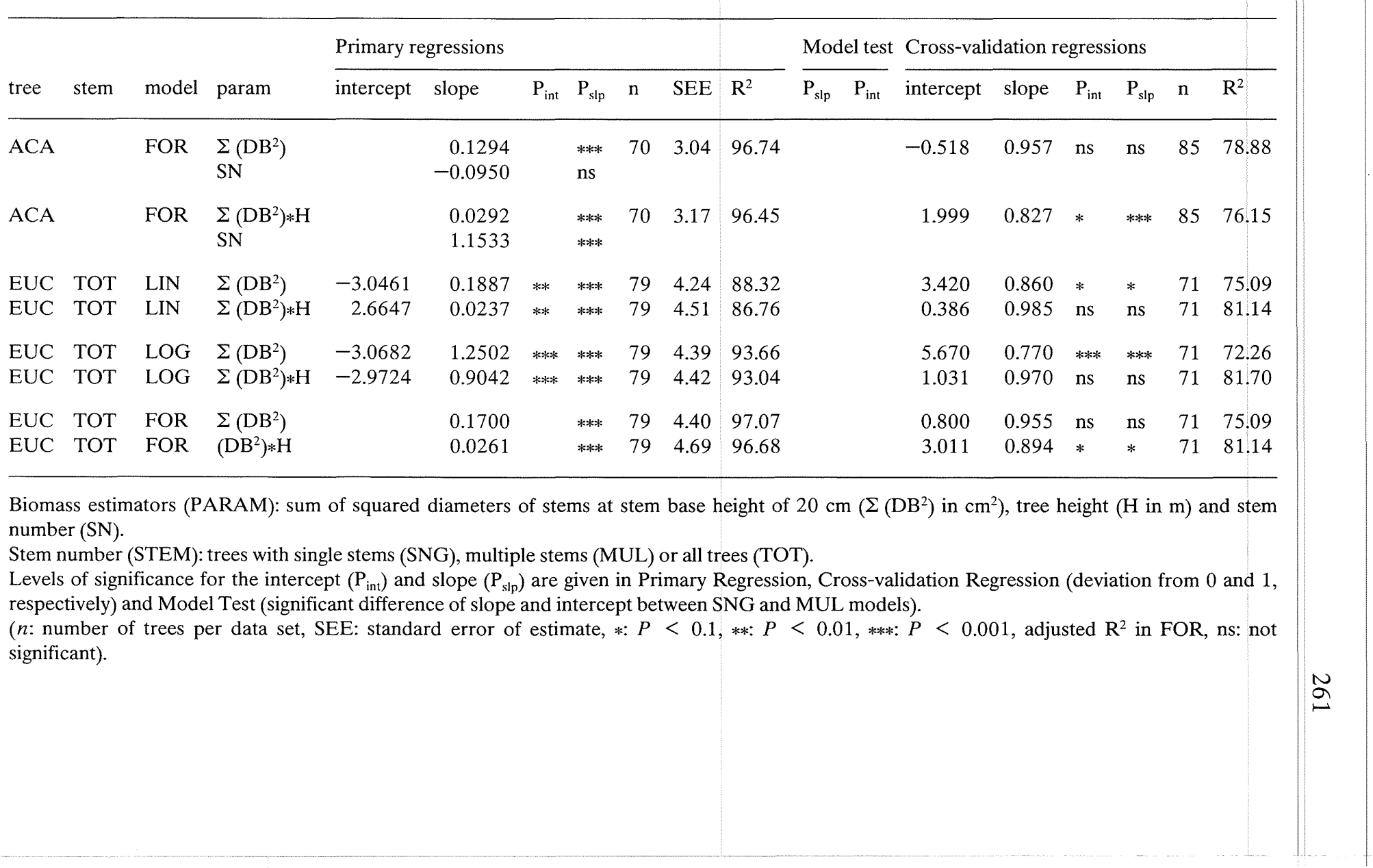


Primary regression equations and cross-validation analyses are presented in Table 2 for both tree species distinguishing between stem type at base, parameter choice and regression models. All regression models were highly significant $(P<0.0001)$. The effects of the different parameters on the models are discussed separately.

\section{Stem number}

Stem number for Acacia and Eucalypt appears to increase from stem base to breast height. Especially Acacia trees, characterized by a shrubby growth form, exhibit multiple stems at base level (60 out of 155 trees used in primary and cross-validation regressions, Table 2). Nevertheless, stem number was not significant in primary regressions for Acacia (Model test, Table 2). In the cross-validation regressions, however, accuracy was not always satisfactory for the LIN and the LOG models with $\Sigma\left(\mathrm{DB}^{2}\right)$, suggesting some bias in this data set. This was not the case when the FOR model was used with $\Sigma\left(\mathrm{DB}^{2}\right)$ as the parameter. Introducing the stem number at base level in a multiple linear regression model, did not improve accuracy and precision in the cross-validation analysis, whereas the corresponding regression coefficient in the primary regression is nonsignificant (SN, Table 2).

The effect of stem number on the Eucalypt models could not be tested properly due to the small number of multiple stem trees (22 out of 150 trees used in primary and cross-validation regressions, Table 2).

\section{Height}

\section{Acacia}

Accuracy was marginally improved in the LOG, unchanged in the LIN models and negatively affected in both FOR models by incorporating $\mathrm{H}$ for all trees. Since precision did not increase appreciably when using the LOG model, there appears to be no need to include $\mathrm{H}$ in the biometric models.

\section{Eucalypt}

Incorporating $\mathrm{H}$ improved the accuracy and precision of the LIN and LOG models. However, the effect on the FOR model was generally negative; although precision improved the accuracy of the models declined $\left(\mathrm{R}^{2}\right.$ and probability levels in the cross-validation regressions, respectively). 


\section{Selection of model}

Compared to the LIN and FOR models, the LOG models with corresponding parameters in general did not improve the precision of the estimation significantly. Moreover, as indicated by the homoscedastic distribution of the residuals (i.e. homogeneous variance) in the LIN model for both tree species (data not shown) a LOG model is not required.

As discussed previously, $\mathrm{H}$ and stem number can be excluded for Acacia. LIN and FOR models produce similar results in the primary regressions (SEE), though accuracy is marginally improved in favor of the FOR model in the cross-validation regressions. When DB is used, it seems reasonable to force the linear model through the origin as no biomass can be expected with $\mathrm{DB}=0$ (Edminister et al. 1980). Hence, the following biometric relationship is selected:

$$
\text { Acacia: } \mathrm{BM}=0.1282 * \Sigma\left(\mathrm{DB}^{2}\right)
$$

Likewise, the following FOR model is selected for Eucalypt allowing biomass estimation with the highest accuracy:

$$
\text { Eucalypt: } \mathrm{BM}=0.1700 * \Sigma\left(\mathrm{DB}^{2}\right)
$$

Since both (FOR) equations are based on DB measures only, they are simple to apply. Nevertheless, precision in biomass estimations for Eucalypt is slightly improved by using the LIN model incorporating $\mathrm{H}$, or $\mathrm{BM}=2.6647+0.0237 * \Sigma\left(\mathrm{DB}^{2}\right) * \mathrm{H}$.

In Figs. 1a and 2a models (3) and (4) are presented. Their crossvalidation is shown in Figs. $1 \mathrm{~b}$ and $2 \mathrm{~b}$, respectively, indicating a good 1:1 fit.

\section{Error analysis}

The magnitude of the relative error in biomass estimation for Acacia and Eucalypt trees as function of $\Sigma\left(\mathrm{DB}^{2}\right)$ per tree (with $\Sigma\left(\mathrm{DB}^{2}\right)<400 \mathrm{~cm}^{2}$ ) is presented in Figs. $3 a$ and $3 b$, respectively. The relative error was computed as the absolute value of:

$$
\left(\mathrm{BM}_{\text {observed }}-\mathrm{BM}_{\text {predicted }}\right) / \mathrm{BM}_{\text {observed }}
$$

where $\mathrm{BM}_{\text {observed }}$ and $\mathrm{BM}_{\text {predicted }}$ represent the measured and calculated BM of cross-validated trees, using primary regressions Eqs. (3) and (4), respectively. Relative errors decrease with an increase in trunk diameter. 

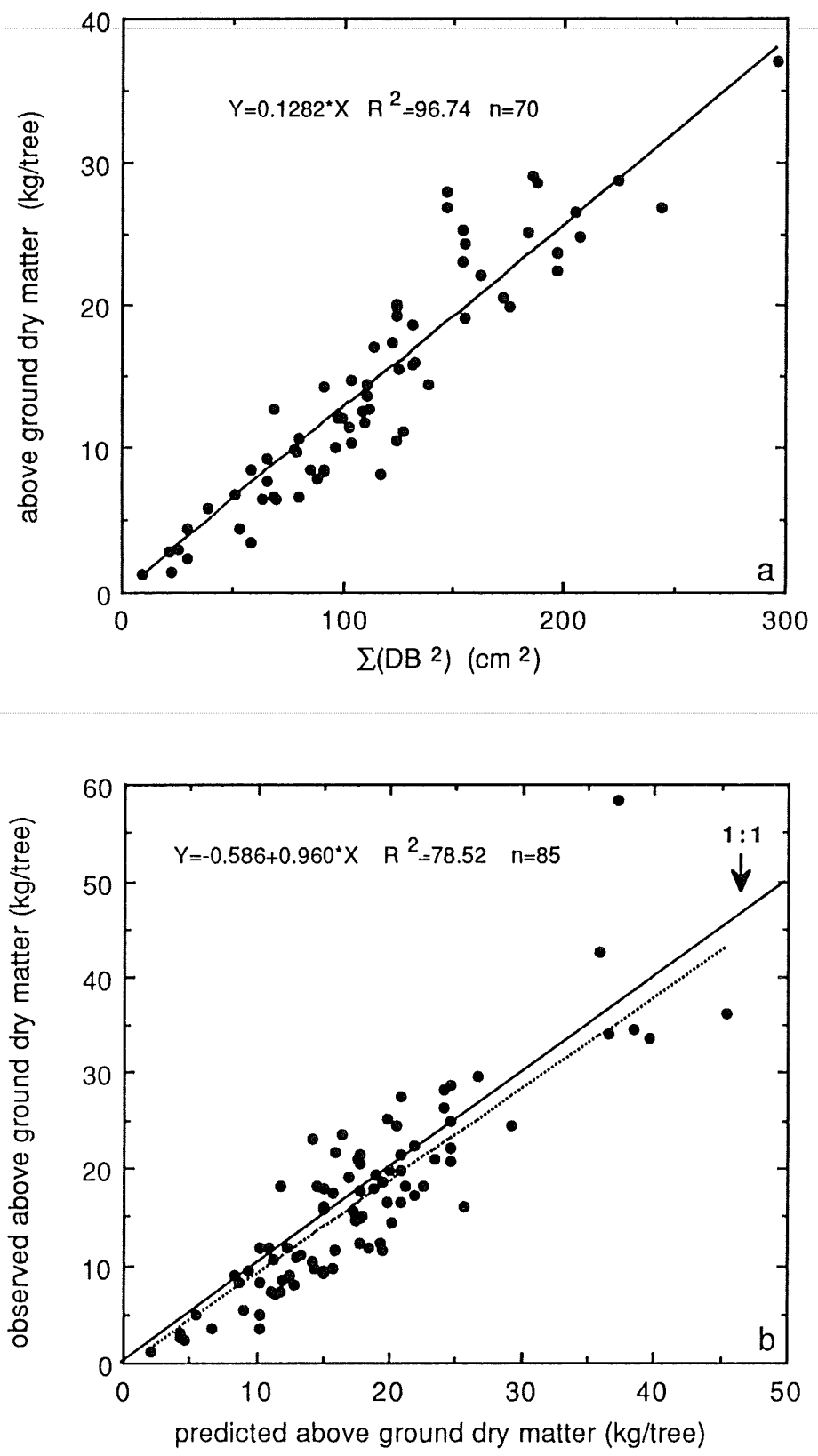

Fig. 1. Acacia salicina : (a) Above ground dry matter $\left(\mathrm{kg} \mathrm{tree}^{-1}\right)$ as a function of the sum of squared diameters of stems at tree base $\left(\Sigma\left(\mathrm{DB}^{2}\right)\right.$ in $\left.\mathrm{cm}^{2}\right)$ - primary regression; (b) Predicted above ground biomass [using Eq. (3)] versus observed biomass - cross-validation regression. 

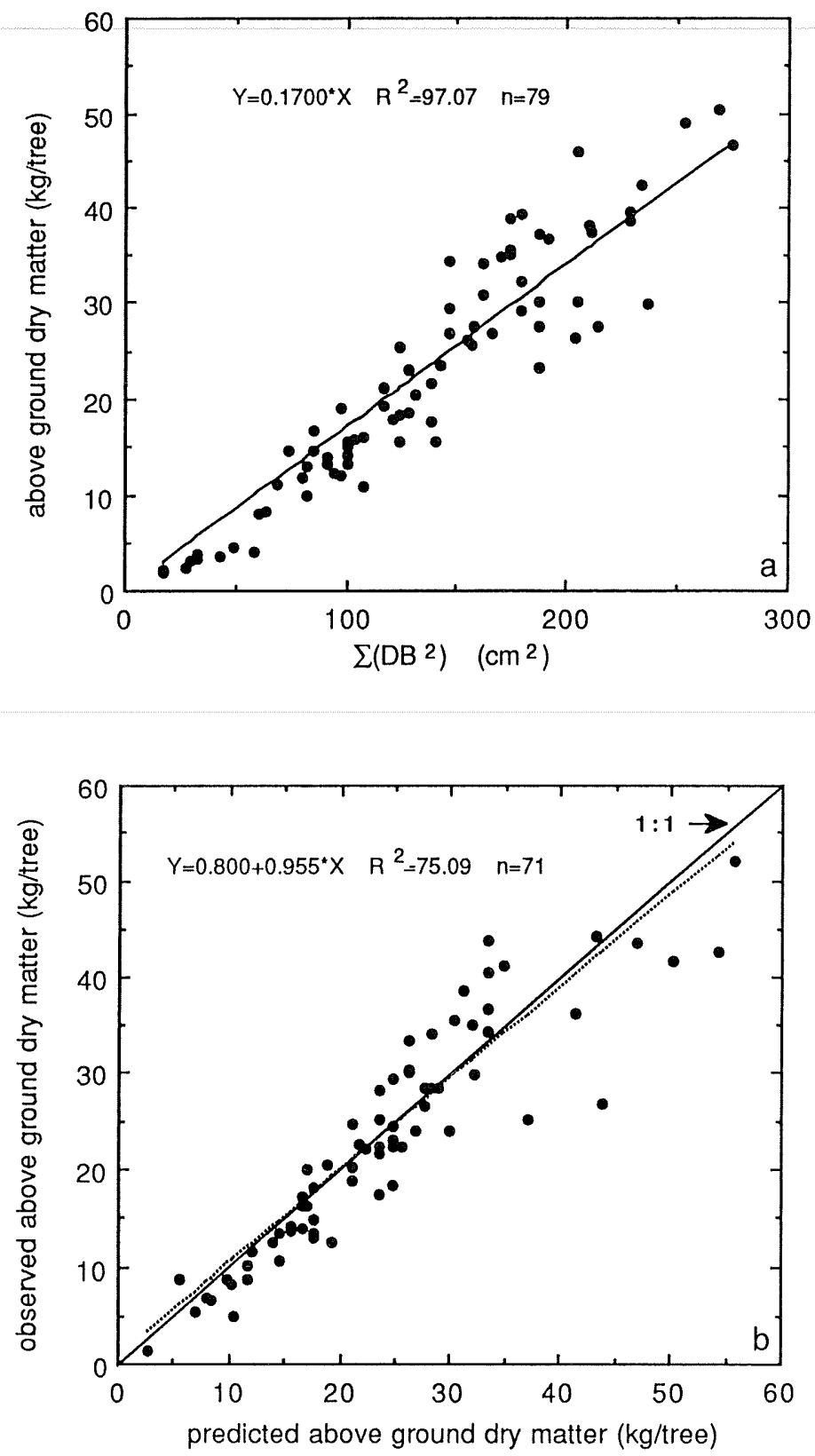

Fig. 2. Eucalyptus occidentalis : (a) Above ground dry matter $\left(\mathrm{kg} \mathrm{tree}^{-1}\right)$ as a function of the sum of squared diameters of stems at tree base $\left(\Sigma\left(\mathrm{DB}^{2}\right)\right.$ in $\left.\mathrm{cm}^{2}\right)$ - primary regression; (b) Predicted above ground biomass [using Eq. (4)] versus observed biomass - crossvalidation regression. 

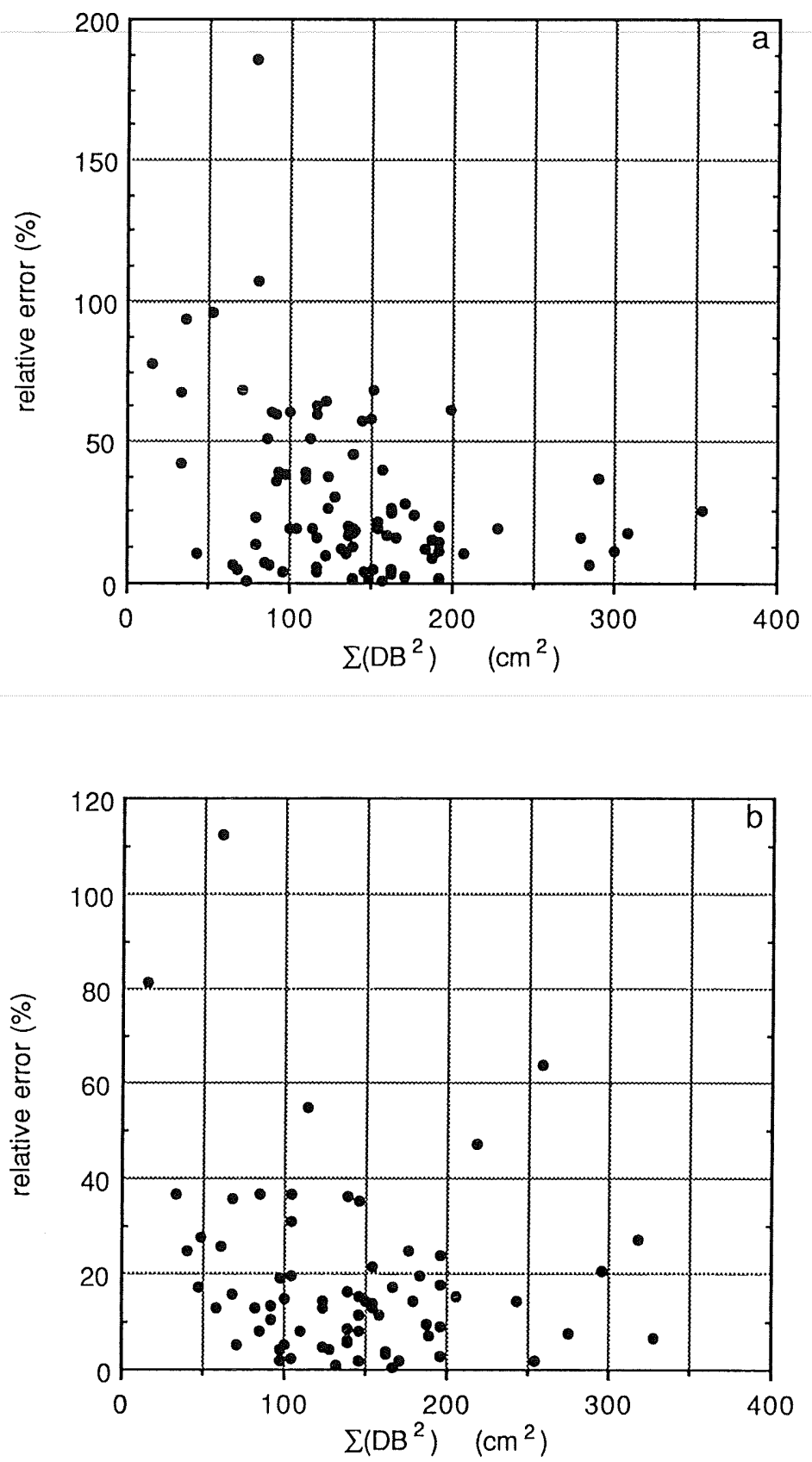

Fig. 3. Relative error (\%) in the estimation of above ground dry matter per tree as function of the sum of squared diameters of stems at tree base $\left(\Sigma\left(\mathrm{DB}^{2}\right)\right.$ in $\left.\mathrm{cm}^{2}\right)$ for (a) Acacia salicina and (b) Eucalyptus occidentalis. 
This phenomenon could be ascribed to the relatively greater influence of the bark on girth measurements of smaller branches (Brack et al. 1985; Kendall Snell and Brown 1978) and to girth measurement error. The latter is directly related to estimated biomass error. Differentiating the FOR model with respect to DB and normalizing by BM, yields

$$
\partial_{\{\mathrm{BM}\}} / \mathrm{BM}=2 \partial_{\{\mathrm{DB}\}} / \mathrm{DB}
$$

If the error in measuring $\mathrm{DB}$ is constant $\left(\partial_{\{\mathrm{DB}\}}\right)$, the relative error in $\mathrm{BM}$ will increase with a decrease in DB. This is in accordance with Fig. 3a, illustrating the dramatic increase in relative error for multiple stem Acacia trees with inherently thin stems (low DB readings).

The effect of tree density on above ground biomass predictions was evaluated by comparing separate regressions for the dense and open treatments (Table 3). No significant differences were found between the slopes of the regressions for both species. The cross-validation regressions, however, showed slopes that were significantly different from 1 for both species in the open treatment. We surmise that this may be due to the relatively small number of trees in the sample.

Tree density may, however, affect the partitioning of BM between foliage and wood. The foliage component may introduce some variation, due to its response to environmental changes (wind, drought stress etc.) (MacDougall et al. 1987). Table 4 presents regressions between $\Sigma\left(\mathrm{DB}^{2}\right)$ and different tree components. The foliage biomass of Acacia trees shows is quite variable (data not shown), which results in low precision. The woody component is much less variable and appears to be the dominant factor in the accuracy of total biomass estimation. Eucalypt foliage biomass is not as variable as that of Acacia and appears to be less affected by environmental conditions.

Foliage to wood ratios at $\Sigma\left(\mathrm{DB}^{2}\right)<100 \mathrm{~cm}^{2}$ for both tree species generally exceed 1 , but level off at 0.81 with a standard deviation of \pm 0.28 for Acacia, and $0.92 \pm 0.19$ for Eucalypt at $\Sigma\left(\mathrm{DB}^{2}\right)$ values $>200$ $\mathrm{cm}^{2}$ (data not shown).

Regression models using $\mathrm{DB}$ or $\mathrm{DBH}$ in combination with $\mathrm{H}$ are presented in Table 5 for single stem Eucalypt (at stem base ánd breast height). The latter restriction seriously reduced the number of available trees as well as the range of stem diameters to be analyzed. Hence, border trees were included as well, after verifying that foliage to wood ratios and diameter classes were similar to those of interior trees. Accuracy and to some extent precision decline when $\mathrm{DBH}$ or $\mathrm{H}$ are included, particularly in combination with the FOR model. It appears that $\mathrm{DBH}$, as apposed to $\mathrm{DB}$, has not reached the minimum size required to serve as biomass 
Table 3. Forced through the origin linear regression models (FOR) for the estimation of above ground dry matter (kg tree ${ }^{-1}$ ) of Acacia salicina (ACA) and Eucalyptus occidentalis (EUC) for two planting densities (DENSE -1250 trees ha ${ }^{-1}$; OPEN -625 trees ha $^{-1}$ ).

\begin{tabular}{|c|c|c|c|c|c|c|c|c|c|c|c|c|c|c|c|}
\hline \multirow[b]{2}{*}{ tree } & \multirow[b]{2}{*}{ treat } & \multirow[b]{2}{*}{ model } & \multirow[b]{2}{*}{ param } & \multicolumn{5}{|c|}{ Primary regression } & \multirow{2}{*}{$\begin{array}{l}\text { Model } \\
\text { test }\end{array}$} & \multicolumn{6}{|c|}{ Cross-validation regression } \\
\hline & & & & slope & $\mathrm{P}_{\mathrm{slp}}$ & $\mathrm{n}$ & SEE & $\mathrm{R}^{2}$ & & intercept & slope & $P_{\text {int }}$ & $\mathrm{P}_{\text {slp }}$ & $\mathrm{n}$ & $\mathrm{R}^{2}$ \\
\hline $\mathrm{ACA}$ & DENSE & FOR & $\Sigma\left(\mathrm{DB}^{2}\right)$ & 0.125 & $* * * * ;$ & 46 & 2.95 & 96.31 & ns & -2.144 & 1.077 & $\mathrm{~ns}$ & ns & 60 & 76.84 \\
\hline ACA & OPEN & FOR & $\Sigma\left(\mathrm{DB}^{2}\right)$ & 0.133 & $* * * * *$ & 24 & 3.08 & 97.61 & & 2.307 & 0.799 & ns & $*$ & 25 & 84.19 \\
\hline EUC & DENSE & FOR & $\Sigma\left(\mathrm{DB}^{2}\right)$ & 0.167 & $* * * * *$ & 57 & 4.14 & 97.00 & $\mathrm{~ns}$ & -2.364 & 1.116 & ns & $\mathrm{ns}$ & 56 & 76.10 \\
\hline EUC & OPEN & FOR & $\Sigma\left(\mathrm{DB}^{2}\right)$ & 0.175 & $* * * *$ & 22 & 4.99 & 97.30 & & 4.940 & 0.781 & ns & $*$ & 15 & 62.10 \\
\hline
\end{tabular}

Biomass estimators (PARAM): sum of squared diameters of stems at stem base height of $20 \mathrm{~cm}\left(\Sigma\left(\mathrm{DB}^{2}\right)\right.$ in $\left.\mathrm{cm}^{2}\right)$.

Levels of significance for the intercept $\left(\mathrm{P}_{\text {int }}\right)$ and slope $\left(\mathrm{P}_{\mathrm{sp}}\right)$ are given in Primary regression, Cross-validation Regression (deviation from 0 and 1 , respectively) and Model Test (significant difference of slope between density treatments).

( $n$ : number of trees per data set, SEE: standard error of estimate, $*: P<0.1, * *: P<0.01, * * *: P<0.001$, adjusted $\mathrm{R}^{2}$ in FOR, ns: not significant). 
Table 4. Forced through the origin linear regression models (FOR) for the estimation of above ground dry matter $\left(\mathrm{kg}^{\mathrm{tree}} \mathrm{e}^{-1}\right)$ of foliage (FOL) and wood (WOOD) in Acacia salicina (ACA) and Eucalyptus occidentalis (EUC).

\begin{tabular}{|c|c|c|c|c|c|c|c|c|c|c|c|c|c|c|}
\hline \multirow[b]{2}{*}{ tree } & \multirow[b]{2}{*}{ treat } & \multirow[b]{2}{*}{ model } & \multirow[b]{2}{*}{ param } & \multicolumn{4}{|c|}{ Primary regression } & \multirow[b]{2}{*}{$\mathrm{R}^{2}$} & \multicolumn{6}{|c|}{ Cross-validation regression } \\
\hline & & & & slope & $P_{\text {slp }}$ & $\mathrm{n}$ & SEE & & intercept & slope & $P_{\text {int }}$ & $\mathrm{P}_{\text {slp }}$ & $\mathrm{n}$ & $\mathrm{R}^{2}$ \\
\hline $\mathrm{ACA}$ & FOL & FOR & $\Sigma\left(\mathrm{DB}^{2}\right)$ & 0.059 & $* * * *$ & 43 & 2.03 & 93.93 & 1.931 & 0.729 & $*$ & $* * *$ & 48 & 53.10 \\
\hline $\mathrm{ACA}$ & WOOD & FOR & $\Sigma\left(\mathrm{DB}^{2}\right)$ & 0.076 & $* * *$ & 43 & 2.29 & 94.68 & -1.552 & 1.149 & $*$ & $*$ & 48 & 81.09 \\
\hline $\mathrm{ACA}$ & TOT & FOR & $\Sigma\left(\mathrm{DB}^{2}\right)$ & 0.1282 & $* * * * *$ & 70 & 3.01 & 96.74 & -0.586 & 0.960 & ns & ns & 85 & 78.52 \\
\hline EUC & FOL & FOR & $\Sigma\left(\mathrm{DB}^{2}\right)$ & 0.088 & $* * * * *$ & 47 & 2.36 & 97.02 & 0.563 & 0.921 & ns & ns & 42 & 79.17 \\
\hline EUC & WOOD & FOR & $\Sigma\left(\mathrm{DB}^{2}\right)$ & 0.090 & $* * * *$ & 47 & 2.54 & 96.55 & 0.004 & 1.013 & ns & ns & 42 & 73.91 \\
\hline EUC & TOT & FOR & $\Sigma\left(\mathrm{DB}^{2}\right)$ & 0.1700 & $* * * *$ & 79 & 4.40 & 97.07 & 0.800 & 0.955 & ns & ns & 71 & 75.09 \\
\hline
\end{tabular}

Biomass estimators (param): sum of squared diameters of stems at stem base height of $20 \mathrm{~cm}\left(\Sigma\left(\mathrm{DB}^{2}\right)\right.$ in $\left.\mathrm{cm}^{2}\right)$

Levels of significance for the intercept $\left(\mathrm{P}_{\mathrm{int}}\right)$ and slope $\left(\mathrm{P}_{\mathrm{slp}}\right)$ are given in Primary Regression and Cross-validation Regression (deviation from 0 and 1 , respectively).

( $n$ : number of trees per data set, SEE: standard error of estimate, $*: P<0.1$, **: $P<0.01$, ***: $P<0.001$, adjusted $\mathrm{R}^{2}$ in FOR, ns: not significant). 
Table 5. Linear (LIN) and through the origin forced linear (FOR) regression models for the estimation of above ground dry matter $\left(\mathrm{kg}\right.$ tree ${ }^{-1}$ ) of single stem Eucalyptus occidentalis (EUC) in relation to different biomass estimators.

\begin{tabular}{|c|c|c|c|c|c|c|c|c|c|c|c|c|c|c|c|}
\hline \multirow[b]{2}{*}{ tree } & \multirow[b]{2}{*}{ model } & \multirow[b]{2}{*}{ param } & \multicolumn{6}{|c|}{ Primary regression } & \multirow[b]{2}{*}{ SEE } & \multicolumn{6}{|c|}{ Cross-validation regression } \\
\hline & & & intercept & slope & $P_{i n t}$ & $\mathrm{P}_{\mathrm{slp}}$ & $\mathrm{n}$ & $\mathrm{R}^{2}$ & & intercept & slope & $P_{\text {int }}$ & $\mathrm{P}_{\mathrm{slp}}$ & $\mathrm{n}$ & $\mathrm{R}^{2}$ \\
\hline EUC & LIN & $\Sigma\left(\mathrm{DB}^{2}\right)$ & -3.489 & 0.200 & $* *$ & $* * * *$ & 55 & 91.16 & 4.00 & 1.154 & 0.913 & ns & ns & 35 & 89.43 \\
\hline EUC & LIN & $\Sigma\left(\mathrm{DBH}^{2}\right)$ & -0.550 & 0.340 & $\mathrm{~ns}$ & $* * * *$ & 54 & 86.97 & 4.82 & 2.384 & 0.893 & * & $*$ & 35 & 91.79 \\
\hline EUC & LIN & $\Sigma\left(\mathrm{DB}^{2}\right) * \mathrm{H}$ & 1.362 & 0.026 & ns & $* * * *$ & 55 & 90.68 & 4.10 & 1.465 & 0.872 & ns & $*$ & 35 & 87.78 \\
\hline EUC & LIN & $\Sigma\left(\mathrm{DBH}^{2}\right) * \mathrm{H}$ & 3.046 & 0.046 & $* * *$ & $* * * *$ & 54 & 87.37 & 4.75 & 2.892 & 0.840 & $*$ & $* *$ & 35 & 88.27 \\
\hline EUC & FOR & $\Sigma\left(\mathrm{DB}^{2}\right)$ & & 0.176 & & $* * * *$ & 55 & 96.31 & 4.34 & -2.032 & 1.038 & ns & ns & 35 & 89.43 \\
\hline EUC & FOR & $\Sigma\left(\mathrm{DBH}^{2}\right)$ & & 0.333 & & $* * * *$ & 54 & 95.59 & 4.79 & 1.893 & 0.911 & $\mathrm{~ns}$ & $*$ & 35 & 91.79 \\
\hline EUC & FOR & $\Sigma\left(\mathrm{DB}^{2}\right) * \mathrm{H}$ & & 0.027 & & $* * * *$ & 55 & 96.62 & 4.15 & 2.653 & 0.829 & $*$ & $* *$ & 35 & 87.70 \\
\hline EUC & FOR & $\Sigma\left(\mathrm{DBH}^{2}\right) * \mathrm{H}$ & & 0.051 & & ***** & 54 & 95.03 & 5.08 & 5.450 & 0.749 & $* *: * * *$ & $* * * * *$ & 35 & 88.20 \\
\hline
\end{tabular}

Biomass estimators (param): sum of squared diameters of stems at stem base height of $20 \mathrm{~cm}\left(\Sigma\left(\mathrm{DB}^{2}\right)\right.$ in $\left.\mathrm{cm}^{2}\right)$, or at breast height $\left(\Sigma\left(\mathrm{DBH}^{2}\right)\right.$ in $\mathrm{cm}^{2}$ ), and tree height $(\mathrm{H}$ in $\mathrm{m})$.

Levels of significance for the intercept $\left(\mathrm{P}_{\mathrm{int}}\right)$ and slope $\left(\mathrm{P}_{\mathrm{sl}}\right)$ are given in Primary Regression and Cross-validation Regression (deviation from 0 and 1 , respectively).

( $n:$ number of trees per data set, SEE: standard error of estimate, $*: P<0.1$, **: $P<0.01$, ***: $P<0.001$, adjusted $\mathrm{R}^{2}$ in FOR, ns: not significant). 
estimator in biometric relationships. This follows amongst others from the larger errors associated with lower diameter readings $(\mathrm{DBH}<\mathrm{DB}$, Table 1) such as the relatively greater influence of the bark as discussed earlier. Moreover, since at breast height a larger number of (smaller) stems per tree were recorded than at stem base (especially in Acacia, Table 1), overall errors in $\mathrm{BM}$ estimations based on $\Sigma\left(\mathrm{DBH}^{2}\right)$ are expected to increase further, as shown previously. However, in view of the above, the effect of DBH measurement errors are expected to decline when trees become bigger. Older trees taper and swell as they become older. At this stage stems at breast height become thicker and therefore the error in estimating biomass and using $\mathrm{DBH}^{2}$ decreases. The trees used in the present studies were young ( 3 years) and did not show signs of either swelling and tapering. Hence, DB should be used.

Although the biometric relationships in this study are for 3 year old seedlings, research is underway to check applicability of these relationships for similar-sized coppice shoots at a three year rotation (Lövenstein and Berliner 1993). Coppice stands maintain high growth rates at short intervals and produce sizeable logs which facilitate felling/lopping, transport and processing. Thus there is a need for additional biometric relationships for small-sized stems.

\section{Conclusions}

The biometric models which best predicted above ground oven dried biomass of individual trees in young Acacia and Eucalypt stands in an arid environment $\left(\Sigma\left(\mathrm{DB}^{2}\right)\right.$ per tree $\left.<400 \mathrm{~cm}^{2}\right)$ are $\mathrm{BM}=0.1282 * \Sigma\left(\mathrm{DB}^{2}\right)$ and $\mathrm{BM}=0.1700 * \Sigma\left(\mathrm{DB}^{2}\right)$, respectively.

The average relative errors in these estimations ranges from $90 \%$ $\left(\Sigma\left(\mathrm{DB}^{2}\right)<100 \mathrm{~cm}^{2}\right)$ to $25 \%\left(\Sigma\left(\mathrm{DB}^{2}\right): 100-400 \mathrm{~cm}^{2}\right)$ in Acacia and from $60 \%$ to $15 \%$ for similar $\mathrm{DB}^{2}$ classes in Eucalypt.

Foliage to wood ratios for both tree species decreased rapidly with increasing DB and stabilized at $\Sigma(\mathrm{DB})^{2}>200 \mathrm{~cm}^{2}$.

Although the models are valid for multi-stemmed trees, large errors are introduced for trees with many stems of small diameter. Since young trees (up to 3-4 years) often exhibit a larger number of small stems at breast height than at stem base (especially trees with a shrubby growth form like Acacia), DB appears a more reliable biomass estimator than DBH.

Plantation density did not affect the goodness of fit of the obtained models.

A cross-validation check using an independent data set appears to be an important criterion to select the best model. Prediction intervals as 
commonly computed in primary regressions refer to the original data set and do not supply further information regarding the bias in these regressions. Lacking similar data on the tree species used under other growing conditions, region wide validation of obtained biometric relationships can as yet not be evaluated.

\section{Acknowledgements}

Arye Rogel, Jossi Goldstein and Sulleman Abuzabuth are gratefully acknowledged for their invaluable field assistance. Technical support during the tree felling was kindly supplied by the Jewish National Fund. Profs H. van Keulen and R. Rabbinge critically reviewed the manuscript.

This study was partially supported by the International Fund and the German Israel Fund for International Research and Development.

\section{References}

Abbott, I. and Loneragan, O. 1982. Growth rate of Jarrah (Eucalyptus marginata) coppice. Aust. For. Res. 13: 16-27.

Abbott, I. and Loneragan, O. 1983. Response of Jarrah (Eucalyptus marginata) regrowth to thinning. Aust. For. Res. 13:217-229.

Agricultural University Wageningen, 1983. International symposium on strategies and designs for afforestation, reforestation and tree planting. Wageningen, the Netherlands.

Bashir, J., Nair, P.K.R. and Kurira, P.W. 1989. Comparative growth performance of some multipurpose trees and shrubs grown at Machakos, Kenya. Agrof. Syst. 9: 17-27.

Brack, C.L., Dawson, M.P. and Gill, A.M. 1985. Bark, leaf and sapwood dimensions in Eucalyptus. Aust. For. Res. 15:1-7.

Bredenkamp, B.V. 1982. Volume regression equations for Eucalyptus grandis on the coastal plain of Zululand. South Afr. For. Jour. 122: 1-4.

Brewbaker, J. 1987. Performance of Australian Acacias in Hawaiian nitrogen-fixing tree trials, pp. 180-184. In: Turnbull J.W. (Ed) Australian Acacias in developing countries. Australian Centre for International Research.

Causton, D.R. 1985. Biometrical, structural and physiological relationships among tree parts, pp. 137-159. In: Cannell, M.G.R. and Jackson, J.E. (Eds) Attributes of trees as crop plants. Natural Environment Research Council.

Chidumayo, E.N. 1988. Estimating fuelwood production and yield in regrowth dry miombo woodland in Zambia. For. Ecol. Mange. 24: 59-66.

Clough, B.F. and Scott, K. 1989. Allometric relationships for estimating above-ground biomass in six mangrove species. For. Ecol. Manage. 27: 117-127.

Edminister, C.B., Beeson, R.T. and Metcalf, G.E. 1980. Volume tables and point sampling factors for Ponderosa pine in the front range of Colorado. Res. Pap. Rocky Mt. For. Range Exp. Stn. RM-218.

Hawkins, T. 1987. Biomass and volume tables for Eucalyptus camaldulensis, Dalbergia sissoo, Acacia auriculiformis and Cassia siamea in the central Bhahar-Terai of Nepal. Oxford Forestry Institute. 
Kendall Snell, J.A. and Brown, J.K. 1978. Comparison of tree biomass estimators - DBH and sapwood area. Forest Sci. 24: 455-457.

Köppen, W. and Geiger, R. 1936. Handbuch der Klimatologie. Bd. 1/M.C., Berlin.

Lövenstein, H.M., Berliner, P.R. and Keulen, H., van. 1991. Runoff agroforestry in arid lands. For. Ecol. Manage. 45: 59-70.

Lövenstein, H.M. and Berliner, P.R. 1993. Regrowth of Acacia salicina and Eucalyptus occidentalis in a three year rotation under rain water harvesting conditions (in preparation).

MacDougall, R.G., Thompson, R.G. and Piene, H. 1987. Stem electrical capacitance and resistance measurements as related to total foliar biomass of balsam fir trees. Can. J. For. Res. 17: 1071-1074.

National Academy of Sciences, 1986. Firewood crops, shrub and tree species for energy production. Washington DC.

Sirin, G. and Mitchell, C.P. 1985. Forest energy and the fuelwood crisis. Proc. IUFRO Project Group 10900. Meeting in Uppsala Sweden, June 8-9, 1984.

Snee, R.D. 1977. Validation of regression models: methods and examples. Technometrics 19(4): 415-428.

Stewart, H.T.L. Flinn, D.W. and Aeberli, B.C. 1979. Above-ground biomass of a mixed Eucalypt forest in Eastern Victoria. Aust. Jour. Bot. 27: 725-740.

West, P.W. 1979. Estimation of height, bark thickness and plot volume in regrowth Eucalypt forest. Aust. For. Res. 9: 295-308.

Whittaker, R.H. and Marks, P.L. 1975. Methods of assessing terrestrial productivity, pp. 55-118. In: Lieth, H. and Whittaker, R.H. (Eds) Primary productivity of the biosphere. Springer Verlag, New York.

Zar, J.H. 1984. Biostatistical analysis, 2nd ed. Prentice Hall Inc.

Zohar, Y., Aronson, J.A. and Lövenstein, H. 1988. Cultivation of multipurpose trees in rain water harvesting systems in the arid zone of Israel. Commonw. For. Rev. 67: 339-349. 
